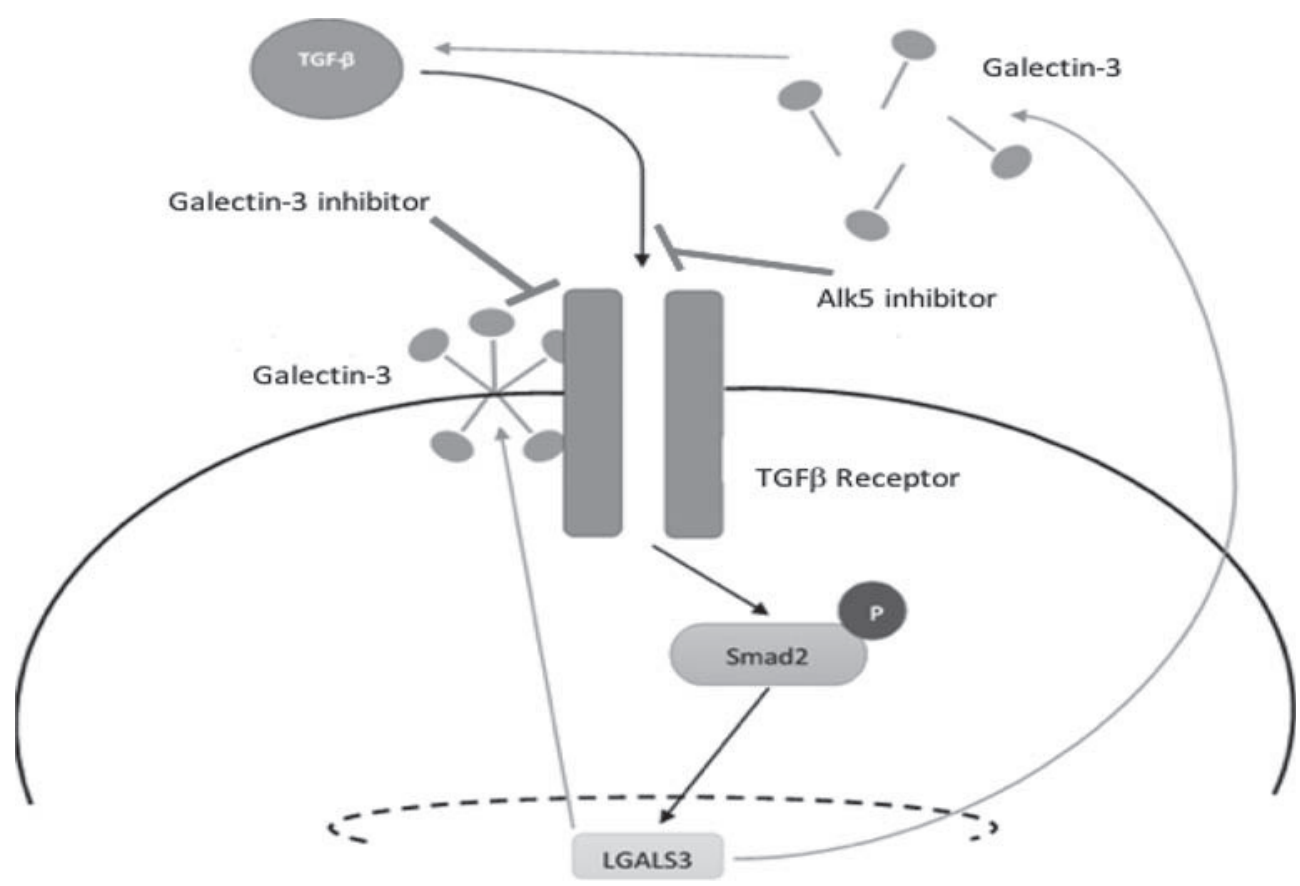

Abstract S76 Figure 1 Proposed view of the TGF $\beta$-galectin-3 feedback loop. TGF $\beta$ activates TGF $\beta$ receptor leading to the phosphorylation of Smad2. Ultimately leading to the upregulation of galectin-3 through increased expression of LGALS3. The increase in levels of galectin-3 leads to the increase in galectin-3 at the cell surface. Cell surface galectin-3 prolongs TGF $\beta$ receptor signalling and activity by preventing its endocytosis ${ }^{1}$ TGF $\beta$ also increases the secretion of galectin-3. ${ }^{2}$ Galectin-3 promotes TGF $\beta$ signalling by activating latent TGF $\beta$

\section{S76 ROLE OF GALECTIN-3 IN THE DEVELOPMENT OF IDIOPATHIC PULMONARY FIBROSIS}

${ }^{1} \mathrm{~N}$ Parmar, ${ }^{1} \mathrm{~A}$ Tatler, ${ }^{2} \mathrm{P}$ Ford, ${ }^{1} \mathrm{G}$ Jenkins. 'University of Nottingham, Nottingham, UK; ${ }^{2}$ Galecto Biotech, Sweden

\subsection{6/thoraxinl-2017-210983.82}

Introduction Idiopathic pulmonary fibrosis (IPF) is a chronic and progressive lung disease with a poor prognosis. Activation of the profibrotic cytokine transforming growth factor $B$ (TGFß) is crucial in IPF development. It has been shown that the $ß$-galactoside binding lectin galectin-3 can promote fibrosis through altering cellular responses to TGFß. ${ }^{1}$ However, the precise mechanism of this is currently unknown.

Methods Immunohistochemistry (IHC) staining for galectin-3 in lung sections from patients with IPF and mice treated with 28 day of saline or bleomycin. Transformed mink lung epithelial cells (TMLCs) which stably express firefly luciferase at the plasminogen activator inhibitor-1 promotor region were used as a measure of TGFß activity. TMLCs were treated with increasing concentrations of recombinant human galectin-3 (rhGal-3) and luciferase activity was measured. Human lung fibroblasts (HLFs) isolated from control patients (non-IPF) and patients with IPF, and immortalised human bronchial epithelial cells (IHBECs) were treated with $50 \mu \mathrm{M}$ TGFß receptor type 1 inhibitor (Alk5 inhibitor), or $1 \mu \mathrm{M}$ galectin-3 inhibitor TD139 (currently in clinical trials for IPF treatment) and $10 \mu \mathrm{g} / \mathrm{ml} \mathrm{rhGal-3.} \mathrm{Mouse} \mathrm{embryonic} \mathrm{fibroblasts} \mathrm{expressing} \mathrm{the}$ integrin avß6 (MEFß6), HLFs, and IHBECs were treated with $1 \mu \mathrm{M}$ TD139 and $2 \mathrm{ng} / \mathrm{ml}$ TGFß. Protein expression of phosphorylated Smad2 (pSmad2) and total Smad2 were assessed by western blot. qPCR was used to measure galectin-3 at the mRNA level in HLFs treated with $2 \mathrm{ng} / \mathrm{ml}$ TGFß.

Results IHC showed that galectin-3 is increased in patients with IPF and in the bleomycin mouse model; where expression is increased in airway epithelial cells, fibroblasts, and macrophages. Treatment with rhGal-3 increased TGFß activity in TMLCs, and significantly increased levels of pSmad2 in HLFs but not IHBECs which was inhibited by the Alk5 inhibitor and TD139. Treatment with the galectin-3 inhibitor TD139 significantly inhibited TGFß dependent Smad2 phosphorylation in MEFß6 and HLFs but not in IHBECs. TGFß stimulation significantly increased galectin-3 expression at the mRNA level in IPF HLFs but not control HLFs. Conclusion Galectin-3 is involved in TGFß signalling where it can promote TGFß activation and activity in fibroblasts. Results indicate the presence of a TGFß-galectin-3 positive feedback loop (figure 1). Thus galectin-3 can potentially be a therapeutic target for IPF treatment.

\section{REFERENCES}

1. Partridge EA. Regulation of cytokine receptors by Golgi N-Glycan processing and endocytosis. Science (80-) 2004;306:120-4. doi:10.1126/science.1102109

2. MacKinnon AC, Gibbons MA, Farnworth SL, Leffler $H$, Nilsson UJ, Delaine $T$, et al. Regulation of transforming growth factor- $\beta 1$-driven lung fibrosis by Galectin3. Am J Respir Crit Care Med 2012;185:537-46. doi:10.1164/rccm.201106$09650 C$

\section{S77 TRANSCRIPTOMIC STUDIES REVEAL MONOCYTE- RELATED GENES AS MAJOR CONTRIBUTOR TO DISEASE ACTIVITY IN PULMONARY SARCOIDOSIS}

${ }^{1} Y$ Kendrick, ${ }^{2} \mathrm{~A}$ Crawshaw, ${ }^{3} \mathrm{H}$ Lockstone, ${ }^{4} \mathrm{E}$ Giannoulatou, ${ }^{3} \mathrm{~K}$ Argoud, ${ }^{4} \mathrm{~S}$ Taylor, ${ }^{1} \mathrm{LP}$ Ho, ${ }^{1}$ Oxford Sarcoidosis Service and MRC Human Immunology Unit, Weatherall Institute of Molecular Medicine, University of Oxford, Oxford, UK; ${ }^{2}$ Respiratory Department, Birmingham Hearlands Hospital, Birmingham, UK; ${ }^{3}$ Wellcome Trust Human Genomic Centre, Oxford, UK; ${ }^{4}$ Computational Biology Research Group, WIMM, University of Oxford, UK

10.1136/thoraxjnl-2017-210983.83

Despite major advances in characterising the disease pathogenesis of sarcoidosis, it is still unclear which immune pathway is 